\title{
Physico-chemical Properties of Mill Scale Iron Powders
}

\author{
Kameswara Srikar SISTA, ${ }^{1)}$ Srinivas DWARAPUDI, ${ }^{2)}$ Deepak KUMAR $^{3)}$ and Gourav Ranjan SINHA ${ }^{3)}$ \\ 1) Principle Researcher, R\&D Tata Steel, Jamshedpur-831001, Jharkhand, India. \\ 2) Principle Scientist, R\&D Tata Steel, Jamshedpur-831001, Jharkhand, India. \\ 3) Researcher, R\&D Tata Steel, Jamshedpur-831001, Jharkhand, India.
}

(Received on November 13, 2019; accepted on January 10, 2020; J-STAGE Advance published date: February 15, 2020)

\begin{abstract}
Powdered form of iron typically $<250$ microns is phrased as iron powder. Commercial manufacturing of iron powder is majorly restricted to atomization, carbonyl, electrolytic and reduction routes. Powders from the later three techniques generally cater to special iron powders applicable to non-powder metallurgy segments such as food fortification, chemical reagents, water purification, etc. In this work, mill scale iron powders are synthesized by thermo-chemical reduction of mill scale, a steel industry by product, and their properties are analysed and compared with commercial iron powders such as carbonyl, electrolytic and reduced. Chemical and physical characterizations such as Optical Microscopy, Scanning Electron Microscopy and X-ray Diffraction of the powders are performed. Obtained results reveal that, mill scale iron powders MIP and MIP45 possess good product properties. Especially, MIP45 grade exhibited finer particle size of $D_{50}<30$ microns and BET surface area of $0.63 \mathrm{~m}^{2} / \mathrm{g}$ along with $\mathrm{Fe}(\mathrm{T})>98 \%$, true density-7.55 g/cc, apparent density $2.67-2.83 \mathrm{~g} / \mathrm{cc}$, packed bulk density of $3.44 \mathrm{~g} / \mathrm{cc}$ and good flowability. This product of mill scale with highest apparent density and good surface area is expected to qualify to new segment of applications along with other commercial iron powders.
\end{abstract}

KEY WORDS: iron powder; carbonyl; electrolytic; by-product; mill scale; reduction.

\section{Introduction}

Powdered form of iron, preferably in the range of 0-250 microns is commercially termed as iron powder. Several approaches like physical, chemical and mechanical methods are used for iron powder production. ${ }^{1)}$ Typical commercial techniques for iron powder production involves; carbonyl iron powder- in which iron scrap is converted into iron pentacarbonyl which is further processed to produce pure, spherical and fine iron powder; electrolytic iron powder- in which iron scrap is processed through batch electrolysis process to get pure, flaky and dendritic iron powder; atomized iron powder- in which molten iron is atomized using pressurized jet of fluid (gas/water) to produce pure, spherical/irregular and coarse iron powder; and reduced iron powder- in which oxides of iron are subjected to carbothermic or hydrogen reduction to produce pure, irregular and coarse iron powder. ${ }^{2}$ Iron powder with diverse sizes, shapes, morphologies and other characteristics combinedly cater to spectrum of applications like powder metallurgy, welding electrodes, bonding magnets, chemical reactions, thermal spray, electrophotography, flame cutting, water purification, friction materials, metal injection moulding, magnetic sorting, food fortification, pharmaceuticals, radar absorption, etc. ${ }^{3)}$ Diversity in powder characteristics is attributed to the source of production and its operating parameters. ${ }^{4)}$ Even

\footnotetext{
* Corresponding author: E-mail: sista.srikar@tatasteel.com DOI: https://doi.org/10.2355/isijinternational.ISIJINT-2019-737
}

though larger volume of applications is catered by atomized powders, special applications like food fortification, chemical reagents and water purification demands iron powder from electrolytic, carbonyl and reduction routes.

By-products management and their effective utilization is one of the prime subject of interest for most of the manufacturing industries. Due to the increasing environmental concern, prime focus of manufacturing giants like steel industry shifted towards waste utilization, especially solid waste utilization. ${ }^{5-9)}$ Conventional approaches of recycling or re-utilizing these wastes using physical, thermal and metallurgical methods is already in practice. ${ }^{10)}$ By-products like LD sludge, BOF Slag, Mill Scale and BF dust which possess high iron are preferably processed through conventional approaches. Mill scale, one of the potential iron bearing by-product from hot rolling mill operations is generally recycled through sintering, cold bonded agglomeration, direct injection, direct reduction and smelting reduction. A different approach of direct reduction recycling of mill scale through "iron powder" synthesis is reported by Sista et al. ${ }^{11)}$ Very few research is available on the hydrogen reduction of Mill scale ${ }^{12-14)}$ and all this research is dedicated towards synthesis process, parameters and kinetics. No dedicated study to evaluate and characterize properties of the iron powders produced from mill scale is available in the literature.

In the present work properties of iron powders synthesized from mill scale, a steel industry by-product, are analysed and compared with few commercially available powders in 
terms of physical, chemical and morphological aspects. The commercial iron powders are chosen from the ones which are targeted for use in special applications segments only. This study will bring into light some potential data related to various iron powder being used in the domain of powdered iron and their readiness to the featured applications.

\section{Materials and Methods}

\subsection{Materials}

5 grades of iron powders (2- Produced inhouse and 3 -commercially available) are used in this study. Reduced iron powder (RIP) and Carbonyl iron powder (CIP) are procured from Sigma Aldrich, USA. Electrolytic iron powder (EIP) of finer grade is procured from commercial manufacturer, India. Mill scale iron powders (MIP and MIP 45) are developed inhouse by thermochemical reduction of mill scale by-product from TATA STEEL. 99.95\% pure XL grade hydrogen gas and $99.99 \%$ pure nitrogen gas is procured from Linde gases limited, India.

\subsection{Methods}

Mill scale a by-product from rolling mill operations of steel plant is thoroughly washed and ground to minus 100 mesh using a laboratory ball mill. The ground powder is used as a raw material to produced mill scale iron powders. Synthesis of iron powders is carried out at $1000^{\circ} \mathrm{C}$ and 4 $\mathrm{h}$ reaction time using the similar methodology discussed by Sista et al. ${ }^{11)}$ Obtained reduced cake is ground to two different size fractions: 1) minus 100 mesh, called MIP and 2) minus 325 mesh, called MIP45. The two grades of iron powders are packed in an air tight bottles and stored for further analysis and usage.

\subsection{Analysis and Characterization}

All the five grades of iron powders chosen for comparison are studied for physical, chemical, structural and morphological aspects. Physical parameters like size, true density, apparent density, packed bulk density, compressibility, etc are studied. Malevern Mastersizer 3000 is used for particle size analysis, Micromeritics Accupyc 1310 for true density analysis, Hosokawa Micron-PT-X powder tester for apparent density, packed bulk density and compressibility. Chemical analysis of the samples is done by wet chemical method. X-Ray diffraction (XRD) study is performed using Panalytical- X'Pert PRO- X-ray diffraction equipment.
Morphological analysis of iron powder is done using FEI Quanta FEG 650 scanning electron microscope (SEM). Optical analysis is performed using Zeiss Axio Imager M2m microscope.

\section{Results and Discussion}

Chemical analysis results of the Mill scale raw material along with commercial as well as synthesized iron powders are tabulated in Table 1. It is observed that the total iron content of all the iron powders are in the range of $98-99 \%$. Metallic iron content (Fe(Met)) defines the purity of iron powders and are in the order of EIP $>$ RIP $>$ CIP $>$ MIP $>$ MIP45. It is observed that oxide as reported in $\mathrm{FeO}$ content of MIP45 is slightly high when compared to other iron powders. This might be due to very slight oxidation of newly generated MIP surface during grinding. On the other hand, mill scale raw material possess $\mathrm{Fe}(\mathrm{T})-72.12 \%$ attributing to magnetite and very small $\mathrm{Fe}(\mathrm{Met})-1.78 \%$ signifies the purity of oxide raw material. It is also evident from X-ray diffraction analysis as shown in Fig. 1(a). No traces of iron and very few peaks of hematite are observed. Most of the mill scale is comprised of magnetite and wustite. The results obtained for the mill scale are similar and in agreement to the XRD, chemistry and particle morphology results reported by many of the researchers'. ${ }^{15-26)}$

Physical analysis results of mill scale raw material as well as iron powder samples are given in Table 2. Theoretical density of iron powder is $7.85-7.89 \mathrm{~g} / \mathrm{cc}^{11)}$ True density of iron powders is the measure of actual density of the product. From the Table 2 it is evident that the true density of iron powders is in the order EIP $>$ RIP $>$ CIP $>$ MIP $>$ MIP45. This result is almost similar to the results obtained from chemical

Table 1. Chemical Analysis of Mill scale raw material and Iron powders (in wt $\%$ ).

\begin{tabular}{ccccccccc}
\hline S. No & Sample & $\mathrm{Fe}(\mathrm{T})$ & $\mathrm{FeO}$ & $\mathrm{Fe}(\mathrm{Met})$ & $\mathrm{MnO}$ & $\mathrm{Al}_{2} \mathrm{O}_{3}$ & $\mathrm{~S}$ & $\mathrm{C}$ \\
\hline 1 & Mill Scale & 72.12 & 46.82 & 1.78 & 0.47 & 0.22 & 0.006 & 0.125 \\
2 & CIP & 98.79 & 1.03 & 96.7 & 0.04 & 0.18 & 0.001 & 0.05 \\
3 & EIP & 98.63 & 0.65 & 97.1 & 0.39 & 0.19 & 0.1 & 0.04 \\
4 & RIP & 98.71 & 0.52 & 96.9 & 0.09 & 0.27 & 0.002 & 0.04 \\
5 & MIP & 98.27 & 0.9 & 96.3 & 0.59 & 0.39 & 0.003 & 0.06 \\
6 & MIP45 & 98.25 & 2.06 & 94.2 & 0.709 & 0.652 & 0.0004 & 0.0415
\end{tabular}

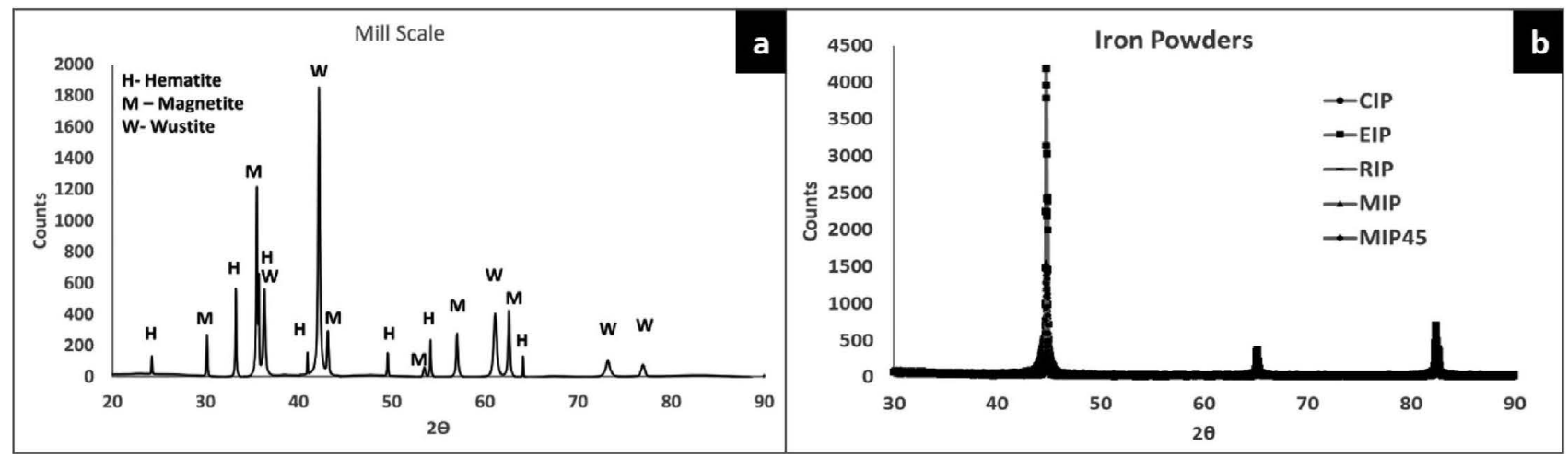

Fig. 1. X-Ray diffraction results of a) mill scale raw material, b) iron powders. 
Table 2. Physical analysis of Mill Scale raw material and Iron powders.

\begin{tabular}{|c|c|c|c|c|c|c|c|c|}
\hline S. No & \multicolumn{2}{|c|}{ Parameter } & Mill Scale & CIP & EIP & RIP & MIP & MIP45 \\
\hline 1 & \multicolumn{2}{|c|}{$\begin{array}{l}\text { True Density } \\
(\mathrm{g} / \mathrm{cc})\end{array}$} & 5.41 & 7.78 & 7.87 & 7.83 & 7.57 & 7.55 \\
\hline 3 & \multicolumn{2}{|c|}{$\begin{array}{l}\text { Apparent Density } \\
(\mathrm{g} / \mathrm{cc})\end{array}$} & 2.49 & 2.52 & 1.17 & 2.55 & 2.00 & 2.82 \\
\hline 4 & \multicolumn{2}{|c|}{$\begin{array}{c}\text { Packed Bulk } \\
\text { Density }(\mathrm{g} / \mathrm{cc})\end{array}$} & 3.43 & 4.35 & 2.35 & 3.20 & 2.68 & 3.44 \\
\hline 5 & \multicolumn{2}{|c|}{$\begin{array}{l}\text { Hausner Ratio } \\
\text { (PBD/AD) }\end{array}$} & 1.37 & 1.72 & 2 & 1.25 & 1.34 & 1.21 \\
\hline 6 & \multicolumn{2}{|c|}{$\begin{array}{c}\text { Compressibility } \\
(\%)\end{array}$} & 27.3 & 42 & 50.1 & 20.5 & 25.1 & 18.1 \\
\hline \multirow[t]{2}{*}{7} & \multicolumn{2}{|c|}{$\begin{array}{l}\text { BET Surface Area } \\
\qquad\left(\mathrm{m}^{2} / \mathrm{g}\right)\end{array}$} & - & 0.45 & 1.2 & 0.13 & 0.49 & 0.63 \\
\hline & \multirow{3}{*}{$\begin{array}{c}\text { Particle size } \\
(\mu \mathrm{m})\end{array}$} & D90 & 109 & 9.93 & 34.6 & 162 & 123 & 45.8 \\
\hline \multirow[t]{2}{*}{8} & & D50 & 33.3 & 4.37 & 13.2 & 89.5 & 65.7 & 30.6 \\
\hline & & D10 & 6.58 & 2.15 & 5.17 & 35.9 & 26.2 & 12.3 \\
\hline 9 & \multicolumn{2}{|c|}{$\begin{array}{l}\text { Span of PSD } \\
\left(\mathrm{D}_{90}-\mathrm{D}_{10}\right) /\left(\mathrm{D}_{50}\right)\end{array}$} & 3.08 & 1.78 & 2.23 & 1.41 & 1.47 & 1.09 \\
\hline
\end{tabular}

analysis of iron powders in the previous section.

Bulk density of iron powders is usually measured as apparent density (AD) and packed bulk density (PBD). AD is the measure of density when the powders are loosely packed whereas PBD of the powder samples is obtained after the loosely packed bed used for AD calculation is densified by means of an external force. In the present work, $\mathrm{AD}$ and PBD measurement is done using PT-X powder tester in which the tapping of loosely packed bed is done for 180 times before calculating the packed bulk density. Pictorial representation showcasing difference between AD and PBD is shown in the Fig. 2.

From the results obtained, it is evident that the $\mathrm{AD}$ of iron powders is in the order MIP45 $>$ RIP $>$ CIP $>$ MIP $>$ EIP. AD of the powders depends on the packing of powder which in turn depends on the particle size, particle shape, particle size distribution (PSD), purity, porosity, etc of the powders. ${ }^{27,28)}$

Particle size analysis of iron powders as shown in the Table 2 reveals that RIP and MIP are a bit coarser with $\mathrm{D}_{90}$ values above 100 microns, MIP45 and EIP powders are finer with $\mathrm{D}_{90}$ values in between $20-50$ microns and CIP powders are extremely fine with $\mathrm{D}_{90}$ values less than 10 microns. Span of the particle size distribution is the measure signifying how wider or narrow the size distribution is. It is given as the ratio of difference between $\mathrm{D}_{90}$ and $\mathrm{D}_{10}$ value to the $\mathrm{D}_{50}$ value of any PSD. ${ }^{29)}$ Particle size distribution of various iron powders is showcased in the Fig. $\mathbf{3}$ and obtained particle span results as reported in the Table 2 reveals that, MIP45 have narrow span of particle size distribution, MIP, RIP and CIP powders have moderate span of PSD while EIP have wider span of PSD.

PBD of iron powders is in the order CIP $>$ MIP45 $>$ RIP $>$ MIP $>$ EIP. It is observed that expect for CIP all other powders followed the similar trend as in AD. Literature reports reveal that a significant increase in bulk density from loosely packed bed to tapped bed is observed due to significant reduction of volume during tapping which occurs due to external force dominating the interparticle force, reduc-

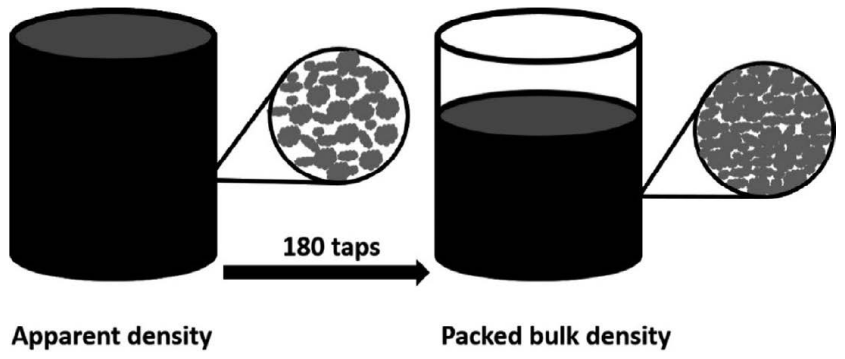

Fig. 2. Illustration of $\mathrm{AD}$ and $\mathrm{PBD}$.

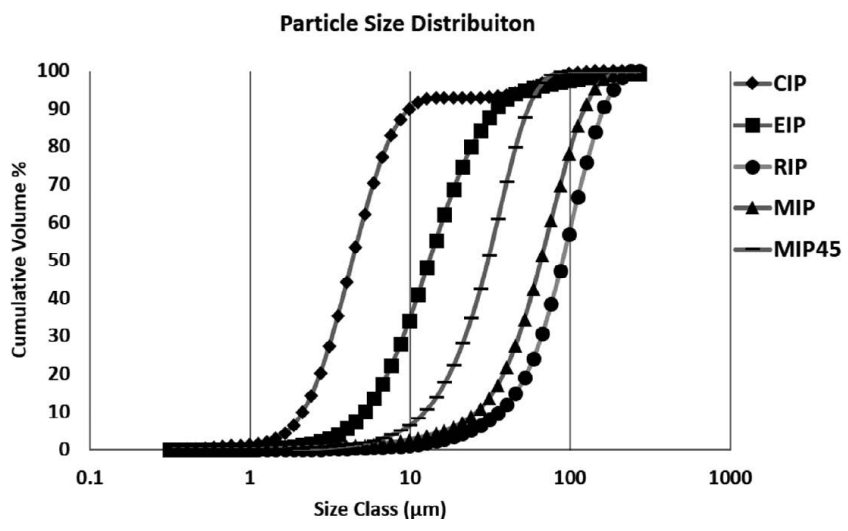

Fig. 3. Particle size distribution of iron powders.

ing the cohesion between the particles and thus resulting in rapid densification..$^{30)}$

Secondary electron images of iron powders at different magnifications obtained from scanning electron microscopy are vividly shown in the Fig. $\mathbf{4}$ and it is observed that, mill scale iron powders (MIP and MIP45) possess irregular morphology compared to pure spherical nature of CIP and flakey/dendritic nature of EIP. RIP possesses similar morphology to mill scale iron powders. In addition to the study on surface morphology obtained from SEM, cross sectional morphology of iron powders is also studied using optical analysis. Obtained results at three different magnifications as showcased in Fig. 5 reveal that mill scale iron powders (MIP and MIP 45) possess irregular and porous morphology compared to spherical, solid and non-porous morphology of CIP. On the other hand RIP powders showcased similar morphology as mill scale iron powders but EIP exhibits dendritic and less porous structures.

Considering the iron powders with similar morphology, MIP, MIP45 and RIP. It is evident that, AD of MIP 45 is highest, followed by RIP and MIP. This sequence of AD is attributed to the finer size fraction of MIP45 compared to MIP. It is also evident from literature that, for powders with similar shape and morphology, smaller size will improve the $\mathrm{AD} \cdot{ }^{28)}$ As a contrary, RIP despite of larger size fraction possesses higher AD than MIP. It is inferred that this behaviour is due to the different method of synthesis and higher purity of RIP compared to MIP.

On the other hand, CIP despite of having super fine size fraction and wider particle span of distribution, possess moderate AD due to its spherical morphology. In a similar way, EIP despite of having fine size fraction, high purity and wider particle size span of distribution, possess lower $\mathrm{AD}$ due to its dendritic or flakey morphology. It is also reported by pavlovic and co-workers that, copper powders 


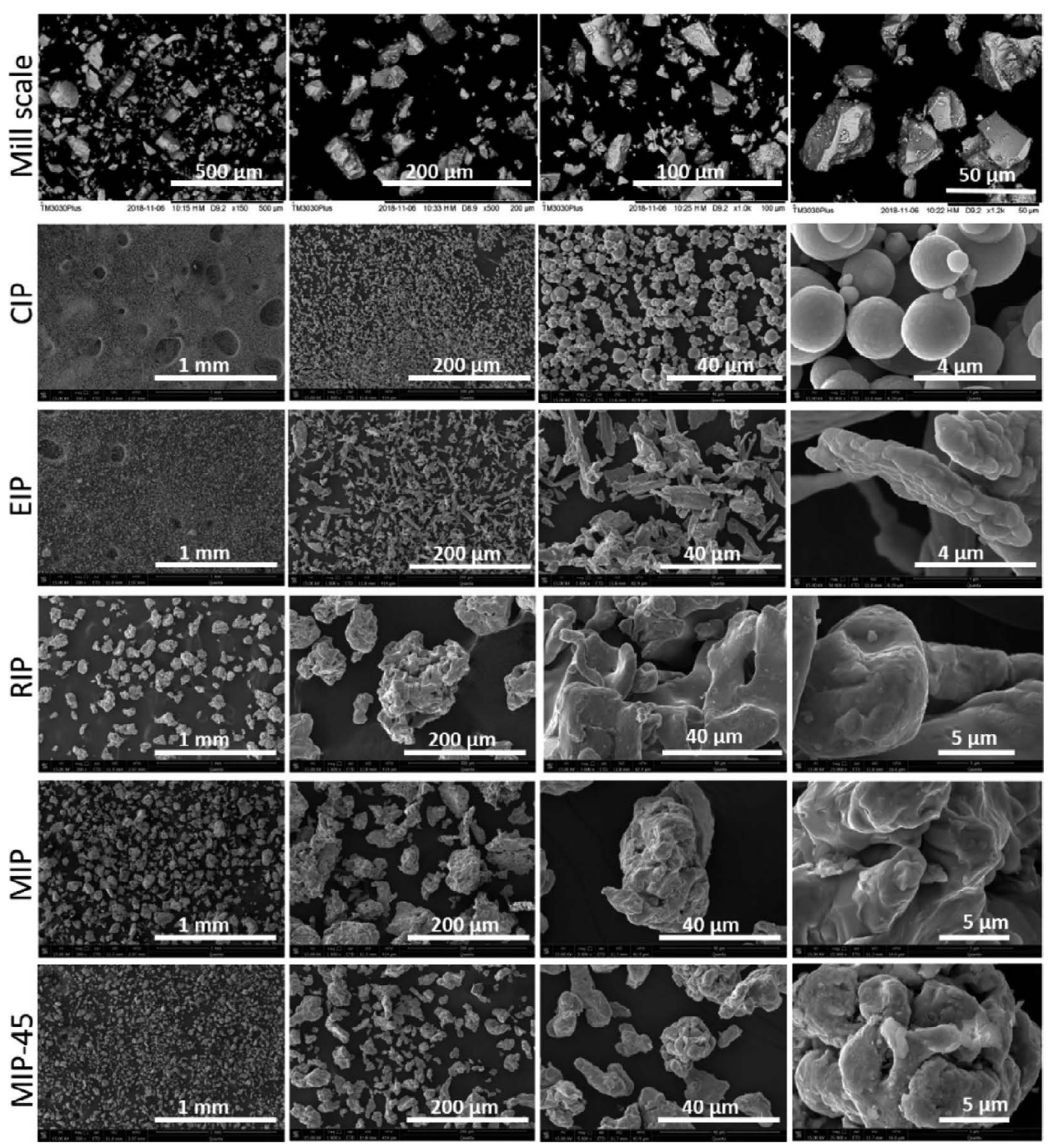

Fig. 4. Scanning electron microscopy-Secondary Electron Image results of Mill scale and Iron powders.

with dendritic nature exhibited very low $\mathrm{AD}$ compared to regular shaped powders. ${ }^{28)}$ Thus, it is evident from the study that apparent density of powder is largely dependent on the shape, morphology, particle size, particle size distribution, purity and porosity of particles. It is the combined effect of all the aforementioned parameters that resulted in the AD of the order MIP45 $>$ RIP $>$ CIP $>$ MIP $>$ EIP.

The ratio of $\mathrm{PBD}$ to $\mathrm{AD}$ is famously called as Hausner Ratio, It is evident from literature that, for particles with similar PSD, farther the morphology differs from spherical, higher will be the hausner ratio. ${ }^{30)}$ Hausner ratio results as shown in the Table 2 reveals that EIP and CIP exhibits higher ratios, while compared to MIP, MIP45 and RIP. Powders with hausner ratio $<1.25$ are considered free flowing, ratio $>1.4$ are poor flowing and ratios in the range 1.25 to 1.4 are passable. ${ }^{31)}$ Thus, MIP 45 and RIP exhibits good flowing characteristic whereas MIP and EIP has poor flowability. On the other hand, even though CIP possess spherical morphology, the high hausner ratio is attributed to its extreme fine particle size and wider span of distribution. One another measure obtained from AD and PBD is compressibility, which is the percentage of ratio of difference in PBD and AD to the PBD. In the present work, it is measured using PT-X powder testing apparatus. PT-X also evaluates flowability of iron powders. It is observed that the compressibility and flowability results of all iron powders obtained are completely in agreement with the results obtained from hausner ratio.

Surface area of a powder particle is generally influenced by its shape, size and morphology. BET surface area analysis of iron powders as shown in the Table 2 is in the order EIP $>$ MIP45 $>$ MIP $>$ CIP $>$ RIP. Mill scale iron powders exhibits higher surface area due to its irregular morphology and porous nature. Among the mill scale ones, MIP 45 exhibits more higher surface area than MIP due to its finer size and availability of new surface imparted while grinding. The highest surface area of EIP is attributed to its dendritic/ flakey morphology and finer size. It is reported in the literature that, particles with high specific surface area possess lower AD and vice versa. ${ }^{28)}$ Thus the lower AD, lower PBD and higher surface area of EIP is attributed to the complex shape (dendritic/flaky) and morphology of the powders.

$\mathrm{X}$-ray diffraction results the iron powders are given in Fig. 1(b). It is evident that all iron powders are pure and crystalline in nature. Within the sensitivity limits of X-ray diffraction measurement, no difference is observed between the various iron powders. These results are in agreement to the purity obtained from the chemical analysis. Thus, above reported discussions reveal that, mill scale iron powders, especially MIP45 exhibits good powder properties with 

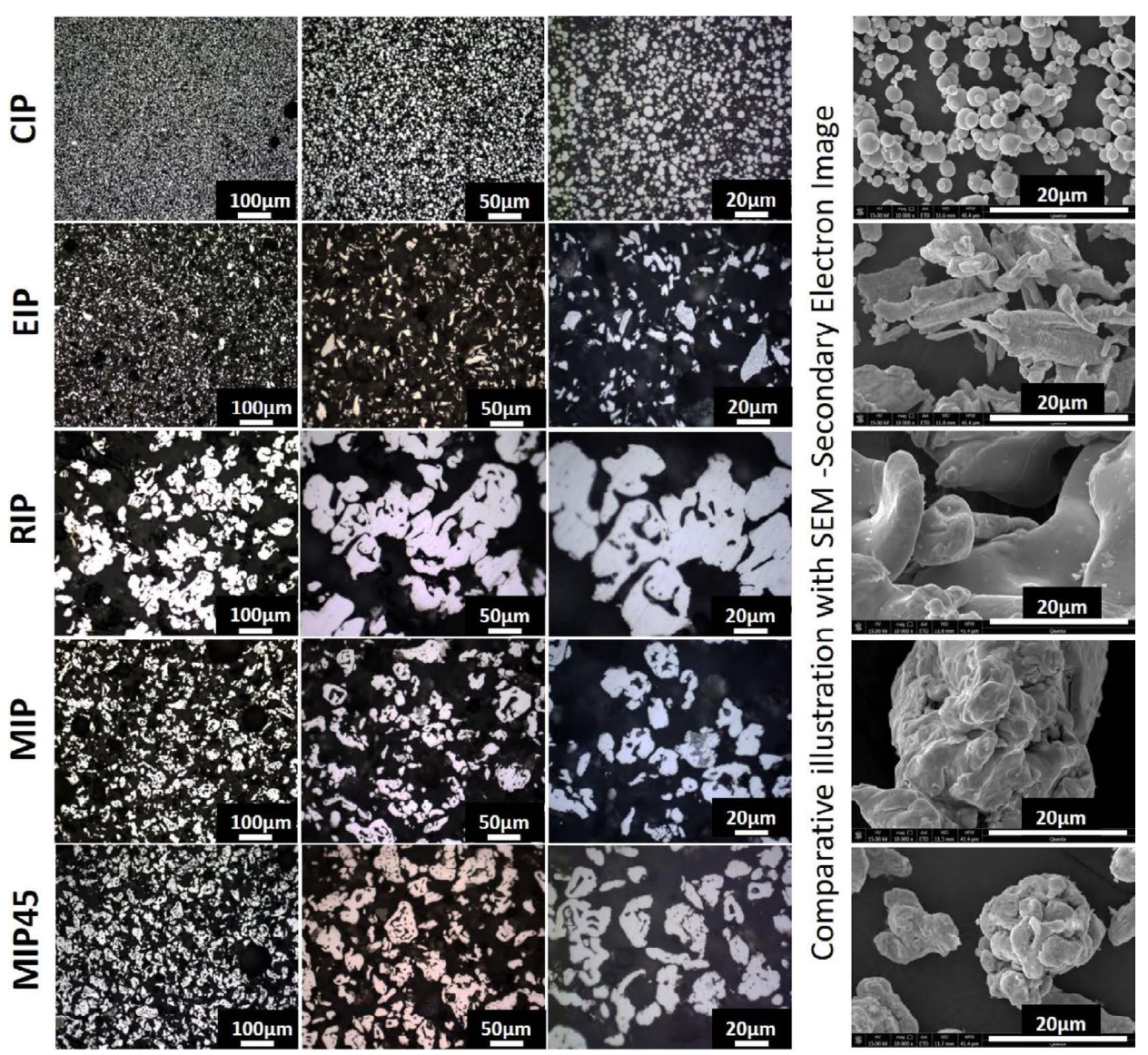

Fig. 5. Optical analysis of Iron powders and comparison vis a vis SEM -Secondary Electron Image. (Online version in color.)

high $\mathrm{AD}$ and $\mathrm{PBD}$, irregular, porous morphology and good flowability.

Physical analysis of mill scale raw material as reported in the Table 2, reveals a coarser particle nature $\left(\mathrm{D}_{90}-109\right.$ microns) with wider span of PSD. Apparent density is in the range of $2.49-2.56 \mathrm{~g} / \mathrm{cc}$ and true density is $5.4 \mathrm{~g} / \mathrm{cc}$. The compressibility and hausner ratio of mill scale raw material are reported as $27.3 \%$ and 1.37 approximately. It is observed that, physical attributes of mill scale are reflected in the iron powders made from it.

Applications of procured commercial iron powders are diversified and are widely used in electronic components, microwave absorption, metal injection moulding, nutrition supplements, ground water remediation, diamond cutting tools, oxygen absorbers, chemical reagents, magnetic wedges, MR fluids, printing and surface coating. ${ }^{32,33)}$ Applicability study of synthesized mill scale iron powders is reported and it is observed that, mill scale iron powders stood applicable for certain applications like, body warmers, chemical reagents, nutrition supplements, water purification and sound insulators. ${ }^{11)}$ In the current study, a finer size fraction of mill scale is further developed to attract few applications which dwell on the finer size like diamond cutting tools, welding rods, friction materials, chemical reagents, environment remediation, etc.

\section{Conclusions}

In this study, Physico-chemical properties of synthesized mill scale iron powders (MIP and MIP45) are extensively studied and are compared with few commercially available iron powders- carbonyl iron powder (CIP), electrolytic iron powder (EIP) and reduced iron powder (RIP). Obtained results conclude that:

(1) Total iron content $(\mathrm{Fe}(\mathrm{T}))$ of mill scale iron powders (MIP and MIP45), is almost comparable to the purity of other iron powders and is in the range of $98-99 \%$ indicating their purity. MIP possess higher metallic content (Fe(Met)) than MIP45.

(2) True density of mill scale iron powders (MIP and MIP45) is greater than $7.5 \mathrm{~g} / \mathrm{cc}$ and is of the order: EIP $>$ RIP $>$ CIP $>$ MIP $>$ MIP45 with EIP, RIP and CIP having values above $7.7 \mathrm{~g} / \mathrm{cc}$.

(3) Particle size analysis of powders reveal that, RIP and MIP powders are a bit coarser with $\mathrm{D}_{90}$ values above 100 microns, MIP45 and EIP powders are finer with $\mathrm{D}_{90}$ values in between 20-50 microns and CIP powders are super fine with $\mathrm{D}_{90}$ values less than 10 microns.

(4) Particle span of distribution reveals that, MIP45 have narrow span of Particle size distribution, MIP, RIP and CIP powders have moderate span of PSD while EIP have wider span of PSD.

(5) SEM analysis of iron powders reveal that, mill scale iron powders (MIP and MIP45) and RIP possess irregular, CIP possess spherical and EIP possesses dendritic/flakey morphologies. Cross sectional morphology results obtained from optical analysis of the powders also supported the above obtained results.

(6) Apparent density (AD) of MIP45 $(2.82 \mathrm{~g} / \mathrm{cc})$ is the highest among the order: MIP45 $>$ RIP $>$ CIP $>$ MIP $>$ EIP 
and Packed bulk density (PBD) of MIP45 (3.44 g/cc) is higher among the order: CIP $>$ MIP45 $>$ RIP $>$ MIP $>$ EIP. This has the influence of powder properties such as finer particle size and irregular morphology.

(7) MIP45 possess good flowability compared to other iron powders with Hausner ratio and compressibility in the order $\mathrm{EIP}>\mathrm{CIP}>\mathrm{MIP}>\mathrm{RIP}>\mathrm{MIP} 45$.

(8) Mill scale iron powders exhibits higher surface areas among the order EIP $>$ MIP45 $>$ MIP $>$ CIP $>$ RIP due to their irregular morphology and porous nature.

(9) XRD results of mill scale iron powders (MIP and MIP45) confirms their pure and crystalline nature along with other iron powders.

\section{REFERENCES}

1) P. C. Angelo and R. Subramanian: Powder Metallurgy Science, Technology and Applications, PHI Learning, Delhi, (2008), 20.

2) K. S. Sista and S. Dwarapudi: ISIJ Int., 58 (2018), No. 6, 999. http:// doi.org/10.2355/isijinternational.ISIJINT-2017-722

3) R. M. German: Powder Metallurgy of Iron and Steel, WileyInterscience, Hoboken, NJ, (1998), 86.

4) A. R. Poster: Iron Powder Metallurgy, Perspectives in Powder Metallurgy, Vol. 3, Springer, Boston, MA, (1968), 20

5) A. Ghosh and A. K. Ghosh: Sustainable Waste Management: Policies and Case Studies, ed. by S. K. Ghosh, Springer, New York, (2020), 299.

6) H. Wu, K. Lv, L. Liang and H. Hu: Omega, 66 (2017), 38. https:// doi.org/10.1016/j.omega.2016.01.009

7) S. Sarkar and D. Mazumder: Int. J. Soc. Behav. Educ. Econ. Bus. Ind. Eng., 9 (2015), 984.

8) M. Smol: J. Steel Struct. Constr., 1 (2015), 1000102. https://doi. org/10.4172/2472-0437.1000102

9) B. Chen, J. Yang and Z. Ouyang: J. Iron Steel Res. Int., 18 (2011), 33. https://doi.org/10.1016/S1006-706X(11)60087-3

10) B. Das, S. Prakash, P. S. R. Reddy and V. N. Misra: Resour. Conserv. Recycl., 50 (2007), 40. https://doi.org/10.1016/j.resconrec.2006.05.008

11) K. S. Sista, S. Dwarapudi and V. P. Nerune: ISIJ Int, 59 (2019), No. 5, 787. https://doi.org/10.2355/isijinternational.ISIJINT-2018-628

12) N. A. El-Hussiny, H. H. Abdul-Waheb, M. M. Ali, A. A. Omar, M E. H. Shalabi and M. R. Moharm: Open Access Libr. J., 1 (2014), 1. http://doi.org/10.4236/oalib.1101016

13) N. M. Gaballah, A. F. Zikry, M. G. Khalifa, A. B. Farag, N. A. ElHussiny and M. E. H. Shalabi: Open J. Inorg. Non-Met. Mater., 3 (2013), 23. http://doi.org/10.4236/ojinm.2013.33005

14) C. Joshi and N. B. Dhokey: Trans. Indian Inst. Met., 68 (2015), 31. http://doi.org/10.1007/s12666-014-0425-4

15) M. Eissa, A. Ahmed and M. El-Fawkhry: J. Metall., 2015 (2015), 926028. http://doi.org/10.1155/2015/926028

16) R. Sen, S. Dehiya, U. Pandel and M. K. Banerjee: Procedia Earth Planet. Sci., 11 (2015), 8. https://doi.org/10.1016/j.proeps.2015.06.003

17) C. Guan, J. Li, N. Tan, Y. He and S. Zhang: Int. J. Hydrogen Energy, 39 (2014), 15116. http://doi.org/10.1016/j.ijhydene.2014.07.024

18) S. Mechachti, O. Benchiheub, S. Serrai and M. E. H. Shalabi: Int. J. Sci. Eng. Res., 4 (2013), No. 5, 1467.

19) M. I. Martín, F. A. López and J. M. Torralba: Ironmaking Steelmaking, 39 (2012), 155. https://doi.org/10.1179/1743281211Y.0000000078

20) N. A. El-Hussiny and M. E. H. Shalabi: Powder Technol., 205 (2011), 217. https://doi.org/10.1016/j.powtec.2010.09.017

21) M. C. Bagatini, V. Zymla, E. Osório and A. C. F. Vilela: ISIJ Int., 51 (2011), 1072. https://doi.org/10.2355/isijinternational.51.1072

22) N. A. El-Hussiny, F. M. Mohamed and M. E. H. Shalabi: Sci. Sinter., 43 (2011), 21. https://doi.org/10.2298/SOS1101021E

23) O. Benchiheub, S. Mechachti, S. Serrai and M. G. Khalifa: J. Mater. Environ. Sci., 1 (2010), 267.

24) R. Farahat, M. Eissa, G. Megahed and A. Baraka: Steel Grips J. Steel Relat. Mater., 8 (2010), 88.

25) J. Shi, D. R. Wang, Y. D. He, H. B. Qi and G. Wei: Mater. Lett., 62 (2008), 3500. https://doi.org/10.1016/j.matlet.2008.03.004

26) S. Cho and J. Lee: Met. Mater. Int., 14 (2008), 193. https://doi. org/10.3365/met.mat.2008.04.193

27) H. Y. Saw, C. E. Davies, A. H. J. Paterson and J. R. Jones: Chemeca 2013, Engineers Australia, Barton ACT, (2013), 299.

28) M. G. Pavlović, Lj. J. Pavlović, E. R. Ivanović, V. Radmilović and K. I. Popov: J. Serb. Chem. Soc., 66 (2001), 923. https://doi.org/10.2298/ JSC0112923P

29) C. Polakowski, A. Sochan, A. Bieganowski, M. Ryżak, R. Földényi and J. Tóth: Int. Agrophys., 28 (2014), 195. https://doi.org/10.2478/ intag-2014-0008

30) E. C. Abdullah and D. Geldart: Powder Technol., 102 (1999), 151. https://doi.org/10.1016/S0032-5910(98)00208-3

31) A. B. Spierings, M. Voegtlin, T. Bauer and K. Wegener: Prog. Addit. Manuf., 1 (2016), 9. https://doi.org/10.1007/s40964-015-0001-4

32) BSAF, Carbonyl Iron Powder, https://www.dispersions-pigments. basf.com/portal/load/fid827906/CIP General PO e.pdf, (accessed 2019-09-14)

33) Industrial Metal Powders, https://imp-india.com/industrial-applications/, (accessed 2019-09-14). 